\title{
Coronary stenting: has the Rubicon been crossed?
}

Is the coronary stent here to stay? Have interventionalists crossed the Rubicon? Or after the initial hype will the stent follow the course of many earlier intracoronary devices: with initial enthusiasm leading to increased use, followed by appreciation and then by familiarity, which will lead inevitably to contempt, disillusionment, and a decline in use?

The first stents were implanted in human coronary arteries in 1986 in an attempt to overcome two major limitations of coronary balloon angioplasty-early abrupt occlusion and late restenosis. ${ }^{1}$ At that time our ideas about stenting were rather primitive: to tack back dissections and flaps against the vessel wall and push aside late restenosis.

We soon learned that use of the first generation of stents was limited by imprecise deployment, frank misplacement and even loss of stents in the arterial system. Furthermore, the unpredictable occurrence of subacute and acute thrombosis, invariably leading to serious clinical sequelae, caused great concern. The stringent anticoagulation regimens that were instituted to prevent this had the side effect of major bleeding complications, most often occurring at the femoral puncture site. These difficulties were the main reasons that in the early nineties the further use of stent implantation was seriously questioned. However, knowledge of the appealing simplicity and the attractive immediate post-procedural result of stenting, which has been generally propagated through the perseverance of pioneering believers, appears finally to have tipped the balance in favour of stenting.

\section{Bail-out stenting}

Stent implantation for acute or threatened closure after balloon angioplasty is a most rewarding treatment which has significantly decreased the need for emergency bypass surgery. Bail-out stenting has a high technical success rate but initial reports showed a high adverse clinical event rate. ${ }^{2}$ Increased experience of rapid stent placement to relieve acute ischaemia has led to quicker decision making in cases of abrupt closure and this, combined with emerging use of ultrasound when adequate stent deployment is in doubt and careful attention to anticoagulation treatment regimens, has already reduced these adverse events. Accordingly, bail-out stenting is no longer regarded as a bridge to surgery but is accepted as a definitive treatment. However, in a few situations, such as refractory suboptimal stent implantation in a vessel supplying a large myocardial area at risk or implantation of a stent in an unprotected left main coronary artery, it may still be wise to refer patients for "semi-elective" bypass surgery.

Glossary

STRESS $=$ Stent restenosis study

Benestent $=$ Belge Nederland stent.

\section{Conditional stenting}

There seems to be a strong trend, in particular among "second generation" interventionists, to treat suboptimal outcome of balloon angioplasty (excluding threatened occlusion) with stent implantation to prevent late restenosis. Although this may make sense intuitively, because stent implantation prevents immediate and late recoil, stenting is now known to provoke a considerable neointimal response that can negate the initial lumen gain and in up to $25 \%$ of patients cause frank restenosis. We should bear in mind that not all of the more modest lumen gain achieved by the balloon will be lost later. Most balloon angioplasty patients fare well and randomised trials should be performed before "conditional stenting" becomes an accepted treatment.

\section{Elective stenting}

The STRESS and Benestent trials have been pivotal to the recent enormous increase in popularity of stents. ${ }^{34}$ Both randomised studies demonstrated a modest improvement in late angiographic outcome (associated with fewer adverse clinical events in the Benestent trial) favouring stent implantation over percutaneous transluminal coronary angioplasty (PTCA). Importantly, fewer stented patients than balloon angioplasty patients underwent repeat target vessel revascularisation for ischaemia. These results are encouraging: but overenthusiastic interventionists should keep in mind that they were obtained in highly selected patients with predominantly stable angina $>3 \mathrm{~mm}$ vessel diameter and $<15 \mathrm{~mm}$ lesion length. According to the accumulated experience of balloon angioplasty with serial quantitative coronary angioplasty, fewer than $30 \%$ of lesions treated in PTCA restenosis trials fall into this category.

\section{Ultrasound and anticoagulation}

The use of intravascular ultrasound for appropriate deployment of the stent has greatly increased our awareness that coronary angiography (even with automated high quality quantitative analysis) is not always good enough to guide coronary intervention. Even when appropriate deployment is achieved according to angiographic judgement, stent underexpansion is all too frequently demonstrated by intravascular ultrasound, indicating the need for high pressure dilatation with larger balloons. ${ }^{5}$ Several randomised trials will soon report whether implantations guided by ultrasound give a better late outcome than those guided by plain angiography.

In the meantime, the classic stringent post-stent anticoagulation regimen consisting of heparin, aspirin, and coumadin has been successfully replaced by the combination of aspirin and ticlopidine, so that the subacute occlusion rate has decreased to less than $2.0 \%$ and groin bleeding problems have been significantly reduced. ${ }^{6}$ Even more remarkable is the $0 \%$ subacute occlusion rate 
demonstrated in the Benestent II pilot trial with the use of a combination of a heparin-coated stent, ticlopidine, and aspirin. ${ }^{7}$ Whether these beneficial results should be ascribed to a better anticoagulation regimen, better stent deployment (using ultrasound and high pressure balloons), or less thrombogenic stents remains a matter of debate.

The fact that nowadays stenting in selected patients by experienced interventionists is a safe procedure undoubtedly will further increase its widespread application.

\section{Stenting in acute myocardial infarction}

The message of a roundup of international expert opinion published in the British Heart fournal ${ }^{8}$ which compared the merits of primary angioplasty with those of thrombolysis could be summarised as "direct" angioplasty performed in highly experienced centres offers more benefit than thrombolysis, because it achieves a much higher rate (more than 90\%) of TIMI flow 3 (shown to be associated with the lowest 30 day mortality of $4 \% v 8.3 \%$ with TIMI flow $0-2^{9}$ ) than the best thrombolytic treatment, with accelerated alteplase (t-PA) (54\%). Nonetheless, economic and logistic consideration and a lack of compelling scientific arguments (the number of patients studied in trials is limited) will for the time being prevent the widespread use of primary angioplasty. The apparent key issue in acute infarction is the opening of the thrombotic occlusion as quickly as possible and as effectively as possible (TIMI flow 3). Balloon angioplasty is usually successful ${ }^{10-12}$ but failure is associated with an adverse outcome. ${ }^{13}$

Until now, implantation of a thrombogenic stent in a thrombotic vessel could have been regarded as tantamount to pouring fuel on the flames. However, a wellconducted study published in this issue of Heart (pages 121-126) has shown the opposite. ${ }^{14}$ In 80 patients with complicated direct balloon angioplasty for acute myocardial infarction, Neumann and colleagues demonstrated that stent implantation was highly effective in restoring vessel patency in $99 \%$ (79 out of 80 patient). The reocclusion rate was remarkably low $(8.5 \%)$ for patients in Killip classes I to III in whom angiographic follow up data were obtained (90\%). Surprisingly, the presence of an angiographically visible thrombus was not predictive of reocclusion. The reported low acute re-occlusion rate is perhaps a little optimistic, because patients who died and patients in Killip class IV were not included in the statistics. In their earlier experience post-stenting antithrombotic treatment consisted of aspirin, heparin, and phenprocoumon; however, in keeping with the current trend, their last 30 patients were treated with aspirin and ticlopidine. None of the patients treated with aspirin and ticlopidine suffered stent thrombosis. This startling result is unfortunately based on too few patients for firm conclusions to be reached. The safety and feasibility of stenting in acute myocardial infarction shown in Neumann et als study show that an important thrombotic hurdle has been overcome and open up the possibility of stenting in acute coronary syndromes.

If these results are confirmed by other studies, the concept and practice of mechanical reopening of occluded vessels in acute myocardial infarction with balloon angioplasty and stenting will undoubtedly intensify discussions about primary angioplasty and may revive the debate about immediate, deferred, and late angioplasty in patients with acute myocardial infarction.

\section{Clinical implications}

The stenting scene is changing rapidly. Many stents are now commercially available and the issue of lesion specific stent implantation is emerging. The issue of post-stent anticoagulation treatment appears to be virtually settled and scientific evidence is accumulating that clinically relevant restenosis is considerably reduced by stent implantation compared with balloon angioplasty.

However, we must bear in mind that so far a highly selected group of patients have been studied in clinical trials of stent implantation (single short lesion, in large vessel, in mainly stable angina). The current clinical challenge is to broaden the indications to smaller vessels, longer lesions, unfavourable morphology, unstable coronary syndromes, and ultimately, multivessel coronary stenting.

We believe that interventionists have crossed the Rubicon, that stenting is here to stay, that it will be used more frequently, and that indications for stenting will gradually expand.

PIM DE FEYTER DAVID FOLEY

Catheterisation Laboratory,

Thoraxcenter Bd 416,

University Hospital Dijkzigt,

Dr Molewaterplein 40,

3015 GD Rotterdam

The Netherlands stents to prevent occlusion and restenosis after transluminal angioplasty. $N$ Engl f Med 1987;316:701-6.

2 Lincoff AM, Topol EJ, Chapekis AT, George BS, Candela RJ, Muller DWM, et al. Intracoronary stenting compared with conventional therapy for abrupt vessel closure complicating coronary angioplasty: a matched case-control study. $\mathcal{F}$ Am Coll Cardiol 1993;21:866-75.

3 Fischman DL, Leon MB, Baim DS, Schatz RA, Savage MP, Penn I, et al. A randomised comparison of coronary stent placement and balloon angioplasty in the treatment of coronary artery disease. N Engl $\mathcal{F}$ Med 1994 331:496-501.

4 Serruys PW, de Jaegere P, Kiemeneij F, Macaya C, Rutsch W, Heyndrick G, et al for the Benestent Study Group. A comparison of balloon-expandable stent implantation with balloon angioplasty in patients with coronary artery disease. $N$ Engl f Med 1994;331:489-95.

5 Nakamura S, Colombo A, Gaglione A, Almagor Y, Goldbeg SL, Maiello $\mathrm{L}$, et al. Intracoronary ultrasound observations during stent implantation. Circulation 1994;89:2026-34.

6 Morice MC, Commeau P, Monassier JP, Riou P, Louvard Y, Guerin Y, et al. Coronary stenting without coumadin. Phase II, III, IV and V. Predictors of major complications [abstract]. Eur Heart $\mathcal{f}$ 1995;16Suppl:249.

7 Serruys PW, Emanuelsson H, Macaya C, Rutsch W, Heyndrickx G Suryapranata $\mathrm{H}$, et al. Benestent-II pilot study: in-hospital results of phase 1, 2, 3, 4 [abstract]. Eur Heart $f$ 1995;16 Suppl:290.

phase $1,2,3,4$ [abstract]. Eur Heart 7 1995;16 Suppl:290.
8 Primary angioplasty in myocardial infarction. International roundup. $\mathrm{Br}$ Heart $f 1995 ; 73: 403-16$.

9 Simes RJ, Topol EJ, Holmes DR, White HD, Rutsch WR, Vahanian A, et al for the GUSTO-I Investigators. Link between the angiographic substudy and mortality outcomes in a large-randomized trial of myocardial reperfusion. Importance of early and complete infarct artery reperfusion. Circulation 1995;91:1923-8.

10 Grines CL, Browne KF, Marco J, Rothbaum D, Stone GW, O'Keefe J, et al. A comparison of immediate angioplasty with thrombolytic therapy for acute myocardial infarction. $N$ Engl 7 Med 1993;328:673-9.

11 Gibbons RJ, Holmes DR, Reeder GS, Bailey KR, Hopfenspirger MR Gersh BJ, et al. Immediate angioplasty compared with the administration of a thrombolytic agent followed by conservative treatment for myocardial infarction. N Engl f Med 1993;328:685-91.

12 Zijlstra F, de Boer MJ, Hoorntje JCA, Reiffers S, Reiber JHC, Suryapranata $\mathrm{H}$. A comparison of immediate coronary angioplasty with intravenous streptokinase in acute myocardial infarction. $N$ Engl $f$ Med 1993;328:680-4.

13 Bedotto JB, Kahn JK, Rutherford BD, McConahay DR, Giorgi LV, Johnson WL, et al. Failed direct coronary angioplasty for acute myocardia infarction: in-h a

14 Neumann FJ, Walter H, Richardt G, Schmitt C, Schömig A. Coronary Palmaz-Schatz stent implantation in acute myocardial infarction. Heart 1996;75:121-6. 